\title{
DESAFIOS DA CONSTRUÇÃO DA CIDADANIA NA METRÓPOLE BRASILEIRA
}

\author{
Luiz Cesar Queiróz Ribeiro*
}

\begin{abstract}
Resumo: $O$ artigo propõe a reflexão sobre os desafios contemporâneos da construção da cidadania no Brasil decorrentes dos efeitos das tendências à segregação e segmentação residenciais das grandes cidades sobre a cultura cívica que fundamentou relações políticas nos processos de democratização ocorridos nas sociedades desenvolvidas.
\end{abstract}

Palavras-chave: cidadania, democracia, metrópoles, desigualdades sociais, segregação residencial.

Os cidadãos urbanos usurparam o direito de dissolver os laços da dominação senhorial - e esta foi a grande inovação, de fato, a inovação revolucionária das cidades medievais do Ocidente em face de todas as outras - a quebra do direito senhorial. Nas cidades centro e norte-européias originou-se o conhecido dito: "o ar da cidade liberta". (Max Weber)

... enquanto o conflito não produz a própria fala dos conflitantes, ele não pode sequer ser enunciado. Em outros termos, será preciso que as forças que se opõem a esses sintomas o nomeiem de alguma forma para que sua decifração possa ser feita. (Francisco de Oliveira)

A democracia é um regime que promoveu a desvinculação do homem das relações de dominação pessoal que marcavam o

\footnotetext{
" Doutor em Arquitetura e Urbanismo pela USP, professor titular do Instituto de Pesquisa e Planejamento Urbano e Regional (CCJE) da Universidade Federal do Rio de Janeiro (UFRJ).E-mail: lcqr@terra.com.br
}

Recebido em 20 jul. 2007 e aprovado em 28 ago. 2007. 
feudalismo. A fundação da cidade expressa a subversão da ordem feudal, na qual o camponês estava atrelado ao proprietário da terra por laços de subordinação pessoal. Por este motivo, esta sociedade era caracterizada pela segregação dos homens em estratos sociais hierarquizados. É na cidade que o homem adquire a emancipação material e moral, como bem demonstrou Max Weber. A ordem social passa a ser associada à emergência do mercado e dos direitos considerados naturais da condição humana. Direitos à liberdade, à propriedade, à segurança e direito de resistência à opressão. A multiplicação das cidades e as formas de vida que elas ensejam levaram à subversão da ordem feudal contra as formas de opressão.

As palavras cidade, cidadão e cidadania foram, historicamente, ganhando o mesmo sentido. Podemos identificar três momentos desta evolução. Na antiguidade clássica, cidadania tem a ver com a condição de civitas pela qual os homens, vivendo em aglomerados urbanos, contraem relações fundadas em direitos e deveres mutuamente respeitados. Posteriormente, à condição de civitas somou-se a de polis, ou seja, o direito de os moradores das cidades participarem nos negócios públicos. Já no século XIX, a condição de cidadania é expandida com a inclusão de direitos de proteção do morador da cidade contra o arbítrio do Estado. No final do século XIX e no início do século XX, a condição de cidadão passa também a expressar os direitos relacionados à proteção social, inicialmente relacionados aos riscos do trabalho assalariado (desemprego, acidente do trabalho etc.) e posteriormente estendidos à própria condição de cidadão.

Este terceiro sentido histórico da palavra cidadania tem a ver com a "descoberta do social", como se expressou K. Polanyi para caracterizar o momento em que a sociedade se dá conta da ameaça de destruição que representava o livre jogo do mercado. Corresponde também ao momento em que era necessário universalizar a condição do trabalho assalariado como pressuposto da industrialização 
capitalista. Cria-se um sistema de proteção social ligado ao salariat, com o qual o capital impõe a subordinação real do trabalho.

O sentido moderno da palavra cidadania expressa, portanto, três focos: o democrático, o liberal e o social. O primeiro é o polis; o segundo, o civitas; e o terceiro, societas. Este último foco tem a ver com a descoberta de que o civitas e o polis somente poderiam existir com o mínimo de Justiça Social. Podemos, então, imaginar uma seqüência: cidadania cívica, cidadania política e cidadania social.

No Brasil, cidade e cidadania não têm a mesma trajetória. Os direitos políticos são conquistas recentes em nossa história. $\mathrm{O}$ escravismo fundou uma sociedade que desde sua origem teve no binômio violência-favor o traço fundamental da relação entre dominantes e dominados e no patrimonialismo o padrão de organização e funcionamento do Estado. Com o advento da República, no final de século XIX, ocorrem apenas mudanças de forma, o favor transformando-se em clientelismo e a violência em exclusão das camadas rurais e urbanas do sistema político. As reivindicações das classes populares são tratadas como "caso de polícia", conseqüentemente por meio das práticas de repressão violenta. A urbanização e industrialização desencadeadas em 1930 geraram pressões do operariado e das camadas populares por incorporação, mas a resposta das classes dominantes oscilará entre o populismo e o autoritarismo, ou seja, sucedâneos do binômio violência-favor. Através da face populista da ditadura do Estado Novo, instituem-se na sociedade brasileira os direitos sociais (proteção ao trabalho, moradia social, etc.) corporativamente distribuídos entre os segmentos da classe operária, como forma de integração política de suas organizações sindicais e profissionais. Duas importantes conseqüências: os direitos sociais nascem de cima para baixo e as organizações da sociedade já nascem tuteladas pelo Estado. Esta é, em breves palavras, a história de uma cidadania que nasce sem polis e atrofiada em sua dimensão de societas. 
Nos anos de 1970 a 1980, conhecemos um intenso movimento de organização e mobilização da sociedade em torno da luta contra o autoritarismo e a favor do reconhecimento de necessidades da população como direitos socais. O resultado foi a conquista da democracia e o surgimento de um programa de reforma social. A Constituição de 1988, considerada como Constituição Cidadã, institucionaliza essas conquistas. Nela estão inscritos os princípios e os mecanismos que asseguram no plano legal a implementação de um Estado Democrático e Social, capaz de finalmente fazê-lo emergir na sociedade na qual aumenta o polis, mas o civitas permanece hipertrofiado pela inexistência do societas. Este é o impasse que vivemos hoje nas cidades brasileiras.

\section{Segregação e desigualdade: a espoliação urbana}

Há uma conexão estreita entre as características das nossas cidades e o padrão de desigualdades prevalecentes na sociedade brasileira. É a vigência dos clássicos mecanismos da acumulação urbana, cujos fundamentos são as próprias desigualdades cristalizadas na ocupação do solo. Vários estudos já mostraram (Kowarick, 1979; Ribeiro,1985, 1996, 1997; Ribeiro \& Lago, 1992), com efeito, que a dinâmica urbana da cidade brasileira tem como base a apropriação privada de várias formas da renda urbana, fazendo com que os segmentos já privilegiados desfrutem, simultaneamente, de maior nível de bem-estar social e riqueza acumulada, na forma de um patrimônio imobiliário de alto valor. Ao mesmo tempo, grande parte da população, formada pelos trabalhadores, é espoliada, por não terem sido reconhecidas socialmente suas necessidades de consumo habitacional (moradia e serviços coletivos), inerentes ao modo urbano de vida. O resultado é a urbanização sem cidades.

A carência habitacional está no centro do nosso problema urbano na medida em que, em razão da exclusão de grande parte da 
população do mercado imobiliário formal, a "solução" do chamado déficit habitacional tem sido a inserção marginal na cidade. Prevalece a lógica perversa, produtora da maior parte dos chamados problemas urbanos: quem está fora do mercado somente tem acesso à moradia à margem da cidade! A nossa urbanização, em conseqüência, é caracterizada pelo permanente e crescente descompasso entre o lento crescimento das cidades e a veloz expansão das suas margens. A urbanização expressa, assim, mais fortemente o processo de desruralização da sociedade do que a generalização da forma urbana de vida. Como podemos chamar a isso de urbanização quando o crescimento das nossas cidades se realiza centralmente pelo aumento do número de moradias que não atendem aos padrões mínimos de habitabilidade que tornam possível a vida em aglomerados urbanos?

Não temos estatísticas seguras sobre a marginalização urbana, até porque é difícil quantificar o que não pode ser reconhecido institucionalmente. Os números sobre a melhoria das condições habitacionais, insistentemente anunciados pelos organismos internacionais, não revelam este lado dramático das cidades. Com efeito, se é verdade que as pessoas não estão mais em casebres de zinco e madeira re-utilizada, como nos primórdios das favelas, vilas, etc., hoje elas moram em casas insalubres e totalmente inaptas à função de sustentação de uma vida digna. Alguns dados sobre a realidade brasileira nos dão uma idéia da marginalização urbana. Cerca de $9 \%$ da população metropolitana mora em setores onde prevalece forte ou extrema precariedade em termos de serviços de saneamento básico. São 6 milhões de pessoas vivendo à margem dos padrões mínimos de acesso a água, esgoto e coleta de lixo. Nas cidades localizadas fora das áreas metropolitanas, a marginalização urbana atinge 21 milhões de pessoas! A subnormalidade habitacional medida pelo IBGE aumentou cinco vezes entre 1991 e 2000. Levantamentos feitos pelo Observatório das Metrópoles nas prefeituras apontam assustadores índices de crescimento de moradias em favelas: na grande São Paulo, 
20\% da população mora em favela, quando em 1970 este índice era de apenas 1\%; na cidade do Rio de Janeiro, este percentual se eleva a $28 \%$; em Salvador a $33 \%$, e em Belém a $50 \%$. Nos últimos dez anos, a população das sete regiões metropolitanas saltou de 37 para 42 milhões de habitantes, e suas periferias conheceram uma taxa de crescimento de $30 \%$, enquanto as áreas urbanas mais centrais não cresceram, no mesmo período, mais de 5\%. Por outro lado, o fato de que apenas cerca de $16 \%$ das moradias construídas no Brasil correspondem à oferta gerada pelo segmento formalizado, no qual a construção e o financiamento são atividades organizadas, nos permite avaliar a extensão da exclusão do mercado.

Tabela 1 - Razão entre renda, anos de escolaridade e raça

\begin{tabular}{|c|c|c|c|c|c|c|c|}
\hline & de 4 a 7 & de 8 a 10 & de 11 a 14 & mais de 15 & $\begin{array}{c}\text { sem } \\
\text { instrução }\end{array}$ & Branco & $\begin{array}{c}\text { Negros e } \\
\text { pardos }\end{array}$ \\
\hline Municipio & Razão & Razão & med_renda & med_renda & med_renda & med_renda & med_renda \\
\hline São Paulo & 0,68 & 0,61 & 0,45 & 0,27 & 0,79 & 0,30 & 0,65 \\
\hline Rio de Janeiro & 0,71 & 0,69 & 0,50 & 0,36 & 0,86 & 0,28 & 0,57 \\
\hline Salvador & 0,80 & 0,63 & 0,57 & 0,23 & 0,82 & 0,23 & 0,50 \\
\hline Belo Horizonte & 0,66 & 0,61 & 0,51 & 0,49 & 0,81 & 0,27 & 0,54 \\
\hline Fortaleza & 0,76 & 0,69 & 0,56 & 0,62 & 0,76 & 0,35 & 0,53 \\
\hline Brasilia & 0,61 & 0,64 & 0,40 & 0,27 & 0,61 & 0,22 & 0,40 \\
\hline Curitiba & 0,69 & 0,61 & 0,55 & 0,42 & 0,71 & 0,35 & 0,55 \\
\hline Recife & 0,72 & 0,62 & 0,57 & 0,76 & 0,81 & 0,34 & 0,50 \\
\hline Manaus & 0,84 & 0,81 & 0,62 & 0,52 & 0,80 & 0,42 & 0,59 \\
\hline Porto Alegre & 0,72 & 0,64 & 0,53 & 0,50 & 0,68 & 0,32 & 0,58 \\
\hline Belém & 0,80 & 0,78 & 0,59 & 0,73 & 0,82 & 0,36 & 0,50 \\
\hline Goiânia & 0,84 & 0,73 & 0,57 & 0,35 & 0,80 & 0,43 & 0,55 \\
\hline Sâo Luis & 0,89 & 0,76 & 0,71 & 1,01 & 0,87 & 0,58 & 0,72 \\
\hline Maceió & 0,67 & 0,65 & 0,43 & 0,08 & 0,77 & 0,22 & 0,44 \\
\hline Terisina & 0,75 & 0,68 & 0,51 & 0,25 & 0,90 & 0,25 & 0,46 \\
\hline Natal & 0,61 & 0,50 & 0,53 & 0,00 & 0,74 & 0,22 & 0,43 \\
\hline Campo Grande & 0,62 & 0,69 & 0,44 & 0,00 & 0,94 & 0,29 & 0,61 \\
\hline João Pessoa & 0,72 & 0,56 & 0,51 & 0,33 & 0,80 & 0,28 & 0,41 \\
\hline Cuiabá & 0,72 & 0,56 & 0,51 & 0,23 & 0,60 & 0,28 & 0,49 \\
\hline Aracajú & 0,77 & 0,63 & 0,51 & 0,18 & 0,83 & 0,25 & 0,37 \\
\hline Florianópolis & 0,60 & 0,54 & 0,25 & 0,00 & 0,47 & 0,26 & 0,39 \\
\hline Macapá & 0,87 & 0,59 & 0,59 & 0,27 & 0,61 & 0,47 & 0,51 \\
\hline
\end{tabular}

Fonte: IBGE. Tabulações Especiais do Censo de 2000 Observatório das Metrópoles

Outra faceta contemporânea da espoliação urbana é o efeito que as desigualdades acumuladas na cidade hoje têm sobre as possibilidades de auferir renda. Sabemos, por exemplo, que o local de moradia age como segmentador do mercado e tem implicações na renda das pessoas. Um chefe de família com baixa escolaridade 
(4 a 7 anos de estudo) morador em favelas no Rio de Janeiro e em São Paulo ganha em média menos $30 \%$ do que ganha um morador do bairro com escolaridade equivalente.

Essa distância entre moradores de favela e dos bairros se repete em todas as capitais, expressando que morar nas favelas é uma desvantagem no acesso às melhores posições do mercado de trabalho.

Outro exemplo concerne à segmentação da acessibilidade no interior das metrópoles. Os custos das tarifas dos transportes públicos cresceram 242\% entre junho de 1994 e agosto de 2003, enquanto a renda média dos segmentos de menor renda diminuiu em 24\%. Tal situação dificulta que as camadas populares possam circular pela metrópole na busca da ocupação transitória, o que explica o crescimento da circulação em bicicletas e a pé.

A crise da mobilidade nas metrópoles brasileiras é responsável hoje por parte do desemprego nas áreas metropolitanas.

\section{Segregação e des-empoderamento: a subcidadania}

Durante as décadas de 70 e 80 assistimos, nas cidades latino-americanas, à emergência de lutas contra os mecanismos da espoliação urbana. Alguns progressos foram obtidos em termos de extensão do direito à cidade aos segmentos populares. Programas de urbanização das favelas e seus correlatos nos outros países latinoamericanos são indícios nesta direção. Alguns desses programas refletem as preocupações dos organismos internacionais com os efeitos regressivos da política econômica neoliberal. No caso brasileiro, em 10 de julho de 2001, foi aprovada a Lei $\mathrm{n}^{\mathrm{o}} 10.257$ - denominada Estatuto da Cidade -, que entrou em vigor em outubro do mesmo ano. Reconhecendo a função social da cidade e da propriedade imobiliária, essa lei oferece uma oportunidade para que 
os governos locais possam retirar a dinâmica da organização urbana dos circuitos da acumulação privada de renda e riqueza geradas pela ação do poder público. A espoliação urbana pode ser combatida pelo reconhecimento das necessidades de reprodução das camadas populares na forma de um direito à cidade.

Porém, começamos o novo milênio com crescentes evidências de que novos mecanismos de espoliação urbana estão emergindo nas cidades, relacionados com o fato de que a segregação e a exclusão habitacional produzem espaços nos quais se verificam a acumulação de desvantagens sociais. São aglomerados urbanos de segmentos sociais vivendo o processo de vulnerabilização social decorrente da precarização do emprego, do desemprego e da perda da renda do trabalho, processo ao qual se somam os efeitos do empobrecimento social, resultantes da desestruturação do universo familiar, do isolamento social, da estigmatização e da desertificação cívica dos bairros em vias de guetificação. Neles, em razão desses processos, torna-se cada vez mais problemático o surgimento de ações coletivas que possam compensar a perda da renda e o relativo abandono pelo poder público. Produz-se, assim, um círculo perverso de despossessão que transforma a marginalização social em exclusão territorial. É nestes aglomerados que se verificam as maiores taxas de repetência e evasão escolar, de mães jovens solteiras, e de jovens que não estudam, não trabalham e tampouco procuram empregos. Por outro lado, estudos sobre a chamada violência urbana têm trazido também evidências da relação entre as taxas de incidência de homicídios e a precariedade urbana.

Em resumo, existem elementos suficientes para afirmar que, em nossas cidades, aos históricos mecanismos de espoliação urbana, se associam mecanismos de vulnerabilização da população. Se, antes, a ausência de democracia retirava dos segmentos trabalhadores os bens e serviços inerentes à vida urbana, hoje a segregação e separação fazem com que uma parte não desprezível da população 
seja crescentemente desabilitada dos recursos necessários ao acesso à renda e aos benefícios urbanos. Aqui faz-se necessário um pequeno comentário sobre o conceito de vulnerabilização. Não podemos tomar esta idéia tal qual ela foi formulada por Robert Castel (1995). Nunca tivemos um salariat, portanto nunca tivemos a experiência de um sistema de proteção e solidariedade sociais associado ao trabalho assalariado, como ocorreu na Europa. No Brasil, a cidade - ou melhor, o bairro popular - cumpriu historicamente este papel, em razão de que a concentração territorial das camadas populares recém-transferidas do campo propiciavam o desenvolvimento de uma economia moral e ações coletivas de reivindicações de bemestar social. Em outras palavras, o bairro popular, com sua vida fortemente comunitária, constituía um hiterland capaz de compensar os efeitos da instabilidade do assalariamento incompleto e da ausência de direitos sociais.

No bairro popular, a violência sempre esteve presente, mas ela não produzia os efeitos desorganizadores como hoje os produz a violência associada ao tráfico de drogas e de armas. Ela cria um clima social e uma cultura que diminuem enormemente a eficácia normativa necessária às práticas e relações de solidariedade, incidentes especialmente nos jovens moradores dos bairros populares. Aqueles que são recrutados pelas organizações criminosas adquirem rapidamente massivos recursos, sejam eles armas ou dinheiro. Por outro lado, o assustador número de mortes de homens jovens gera um clima social em que o encurtamento dos horizontes de tempo dos jovens os conduz a atitudes pouco propícias à aceitação dos valores da sociedade.

Luiz Eduardo Soares (2000) aponta os seguintes efeitos da violência:

a) Desorganização da vida associativa e política das comunidades. 
b) Imposição de um regime despótico nas favelas e bairros populares.

c) Recrutamento da força de trabalho infantil e adolescente.

d) Disseminação de valores bélicos, contrários ao universalismo democrático e cidadão, fazendo com que os princípios de orientação dos comportamentos sociais, especialmente dos jovens, sejam aqueles ligados à lealdade, honra e coragem, próprios de uma sociedade feudalizada, havendo retração dos valores civilizatórios que habilitam seu portador com disposições subjetivas para o respeito às regras da sociabilidade, e para a racionalidade estrategicamente orientada.

e) Como conseqüência, nos bairros populares, observa-se o predomínio agressivo dos valores da guerra feudalizada, fundados na crença da supremacia da coragem e da lealdade, o que leva, invariavelmente, a um quadro social de faccionalismo fratricida.

f) Destruição das estruturas familiares e da dinâmica da reprodução cultural ao se inverterem as relações de autoridade intergeracionais, convertendo-as em laços de poder militarizado. Em decorrência da vigência destes valores, há, nos bairros populares, uma permanente disputa em torno da supremacia moral de duas estruturas de hierarquia: a familiar e a do tráfico. A conseqüência é a degradação da "lealdade comunitária tradicional, substituindo-a por relações exclusivistas com grupos paramilitares e por um narcisismo consumista extremo". Nos bairros em que o tráfico tem presença marcante, "a identidade predominante passa a ser o grupo criminoso, que usa o vínculo simbólico de uma das grandes 'famílias' do tráfico.... para diferenciar-se dos rivais. Esse processo tende 
a ser mais traumático quando os traficantes são invasores, isto é, não originários da favela que dominam".

g) Fortalecimento e disseminação do patriarcalismo, da homofobia e da misoginia.

h) Estimulação de reações que tendem a estigmatizar a pobreza e os pobres, promovendo imagens negativas das comunidades dos bairros populares, que passam a ser vistos como fontes do mal. Essas imagens inspiram e reforçam práticas discriminatórias da sociedade como um todo em relação às favelas e aos bairros populares, sobre os quais passam a vigorar concepções e discursos estigmatizadores. Bem sabemos, a partir dos resultados das pesquisas de Wacquant (2001) sobre os guetos negros de Chicago e sobre as periferias pobres de Paris, que o estigma acaba sendo incorporado pelos estigmatizados, o que os leva a comportamentos orientados pela busca em se dissociar desses lugares.

\section{Segregação e poder corporativo: os hipercidadãos}

A noção de overclass proposta por alguns analistas para descrever a crescente polarização em curso nas sociedades centrais entre os segmentos sociais que integram os atuais circuitos dinâmicos da economia, em especial os das altas finanças, e os 'perdedores' das transformações econômicas, serve para também descrever a evolução das históricas distâncias sociais entre as camadas superiores e o conjunto da população da sociedade brasileira. Ao que parece, constata-se a convergência dos padrões de desigualdades entre o Brasil e os outros países centrais. Apenas para fornecer uma ilustração das distâncias entre o topo e a base da hierarquia social, nos bastam as informações contidas na tabela que indica a evolução 
da renda apropriada pelos ricos $(10 \%)$ e os 'super-ricos'(1\%) da sociedade brasileira nos últimos decênios.

\section{Tabela 2 - Razão entre as rendas dos estratos sociais no Brasil Metropolitano}

\begin{tabular}{l|c|c|c|c}
\hline Estratos & $\mathbf{1 9 8 1}$ & $\mathbf{1 9 8 8}$ & $\mathbf{1 9 9 5}$ & $\mathbf{1 9 9 9}$ \\
\hline Ricos/Pobres & 17,5 & 23,8 & 20,8 & 18,6 \\
Super-ricos/Pobres & 44,3 & 64,5 & 55,7 & 49,0 \\
\hline
\end{tabular}

Fonte: PNADs, IBGE. Tabulação especial Observatório de Políticas Urbanas e Gestão Municial (IPPUR/UFRJ - FASE)

É impossível nos limites deste ensaio retraçar os fundamentos históricos da constituição da tal regime de desigualdades sociais na sociedade brasileira. Basta afirmar que a expansão industrial entre nós não realizou o mito de uma sociedade competitiva, na qual o mercado passa a ser o distribuidor das oportunidades de participação na distribuição da riqueza. Para Celso Furtado (1981), a questão distributiva tem centralidade na explicação dos impasses históricos da sociedade brasileira. Entretanto, ao contrário do que muitos economistas defendem, Furtado entende que a chamada problemática da distribuição da renda é a tradução econômica de uma estrutura de poder sustentada por uma correlação de forças altamente favorável aos interesses da elite econômica, social e política, que se organiza na forma de um poder corporativo. A nosso ver, a cidade brasileira tem sido gerida por uma forma específica desse poder corporativo, representado sobretudo pelos principais atores que participam da acumulação urbana: capital imobiliário, capital empreiteiro, capital concessionário e capital patrimonial.

O poder corporativo das classes superiores se instala na cidade como resultado do processo histórico de formação econômico-social da sociedade brasileira e estaria alicerçado no fato da industrialização ocorrida nos pós-guerra ter sido politicamente sustentada por uma "sagrada aliança" (Lessa \& Dain, 1984) entre interesses locais, a 
burguesia associada e o Estado. As duas cláusulas desta aliança podem ser sintetizadas na garantia de esferas de acumulação entre burguesia local e as firmas internacionais e na construção de mecanismos institucionais de redistribuição do lucro. Não é por outra razão que Oliveira (1982, p. 50-51) já afirmava na década de 80 que "o urbano hoje no Brasil são as classes médias".

Essas considerações nos reconduzem ao ponto central desse artigo, ou seja, à relação entre a cidade e a cidadania, ou melhor, a hipercidadania das classes médias. Desde a década de $90 \mathrm{vem}$ ocorrendo a re-configuração do poder corporativo urbano, com a entrada de novas forças sociais representando as novas frações econômicas presentes na cidade. A sua principal característica é a construção de acordos estratégicos entre os antigos e os novos interesses da acumulação urbana e a busca de legitimação através do marketing urbano, com a utilização da intervenção pública na cidade, abandonando-se, portanto, a política de compromisso como instrumento de integração subordinada das camadas populares. Tem enorme importância nesse processo o comportamento político do segmento das classes médias, fortemente orientado por preocupações defensivas e separatistas. Por isso mesmo, a diferenciação entre ocupação manual e não-manual define importante corte da estrutura social brasileira, estabelecendo fronteiras e padrões de mobilidade ocupacional e a diferenciação entre as categorias médias e superiores expressa importante distância social em termos de estilo de vida e acessibilidade aos recursos sociais e econômicos.

A densidade social e política das classes médias nas cidades brasileiras pode também ser entendida pela sua forte presença nas organizações da sociedade civil. Os dados do levantamento sobre associativismo e cultura cívica realizado pelo IBGE em 1996, como suplemento da Pesquisa Mensal deEmprego (PME) de fevereiro desse ano, mostram-nos algumas evidências nesta direção. Nele, procurouse levantar uma série de informações sobre a filiação/associação das 
pessoas maiores de 18 anos às entidades civis dos seguintes tipos: sindicato, associação profissional, associações esportivas e culturais, associações religiosas, associação de bairro e órgãos comunitários em geral. A leitura dos dados permite identificar que a metrópole do Rio de Janeiro apresenta um baixo grau de associativismo. Em primeiro lugar, observa-se que, em 1996, 24\% de pessoas de 18 anos ou mais de idade estavam associadas ou filiadas a organizações associativas. Esse índice estava abaixo da média nacional, já que, tendo por referência seis regiões metropolitanas no Brasil, do universo de 22,5 milhões de pessoas de 18 anos ou mais de idades, $27 \%$ tinham vínculo com algum tipo de organização associativa. Comparando-se com as demais regiões metropolitanas, percebemos que o grau de associativismo fluminense é próximo ao das regiões metropolitanas de São Paulo (29\%), Belo Horizonte (25\%), Recife (24\%) e Salvador (22\%). ${ }^{2}$ Tendo-se como referência as organizações sindicais, as que ostentam maiores índices de associação, verificase claramente que camadas sociais que estão mais organizadas, em todas as regiões metropolitanas, são as que têm maior escolaridade e maior renda, o que traduz o poder social das classes médias na sociedade urbana brasileira.

A crescente concentração territorial das camadas superiores tem forte implicação na espacialização do poder social das classes médias nas metrópoles brasileiras, como bem evidenciam os estudos comparativos em curso. Com efeito, o grau de associativismo e participação político-social, bem como os tipos de organização predominantes mostram-se diferenciados segundo as áreas da metrópole. Assim, por exemplo, constata-se que os núcleos centrais das metrópoles concentram maior percentual de pessoas associadas do que as cidades periféricas (por exemplo, a cidade do Rio de Janeiro concentra $27 \%$ de pessoas associadas e as cidades da sua periferia, na região da Baixada Fluminense, 17\%). Além disso, a análise intrametropolitana do grau e modalidade da participação confirma, em grande medida, a clássica distinção núcleo/periferia. As áreas 
centrais, onde vem se verificando com maior força o fenômeno da auto-segregação das camadas superiores, apresentam os mais altos níveis de adesão às entidades sindicais, profissionais, esportivas e culturais, que são menores nas áreas periféricas. Em sentido inverso, os níveis de filiação a entidades religiosas e comunitárias mostram-se significativos em áreas periféricas, incorporando predominantemente segmentos populacionais de baixa escolaridade e rendimento.

\section{Cidadania na cidade partida?}

Os núcleos das nossas metrópoles são constituídos, cada vez mais, por aglomerados urbanos cujos dinamismos econômico e social decorrem de seus papéis nas redes globais de circulação mercantil e financeira. É a cidade alta, onde o moderno mercado é dominante, centro logístico dos negócios, aonde chegam as informações, as mercadorias, os capitais, os créditos. Nesta parte, quem dita as leis são os donos do capital e das outras formas de riqueza, e seus habitantes se orientam por uma cultura cosmopolita. Nas periferias geográficas e sociais, cresce uma massa marginal, desconectada produtivamente dos espaços onde a riqueza se reproduz e se acumula. Nelas se expande uma economia da sobrevivência fechada por si mesma. O poder funda-se na privatização da violência, organizada em estruturas feudalizadas. São áreas nas quais a população tem que se esforçar para não sucumbir integralmente aos valores e às práticas inerentes ao capitalismo predador, gerado pelos diversos circuitos da criminalidade que gravitam em torno do tráfico de armas e de drogas, e ao capitalismo assistencialista, fundado na total submissão da população carente aos laços de dependência e favores pessoais com aqueles que controlam as inúmeras instituições "filantrópicas" das nossas periferias e favelas. Uma ou outra forma de dominação estimula a consolidação de uma cultura muito pouco favorável à ação coletiva e aos valores igualitários, indispensáveis à democracia. 
Esta paisagem lembra a descrição que fez o historiador F. Braudel (1996) sobre a disjunção ocorrida na época da formação da economia-mundo entre os planos e o tempo da vida material e quotidiana da maioria da população, que construía a sua sobrevivência diária praticamente à margem da rede de trocas organizada sob a hegemonia das "altas finanças" que atravessava as regiões da Europa.

O centro, o 'coração', reúne tudo o que há de mais avançado e de mais diversificado. $\mathrm{O}$ anel seguinte só tem uma parte dessas vantagens, embora participe delas: é uma zona dos 'brilhantes secundários'. A imensa periferia, com seus povoados pouco densos, é, ao contrário, o arcaísmo, o atraso, a exploração fácil por parte dos outros. Essa geografia discriminatória ainda hoje logra e explica a história geral do mundo, se bem que esta, ocasionalmente, também crie por si mesma o logro com a sua conivência (Braudel, 1996).

Na cidade da globalização periférica, os efeitos dos novos mecanismos de vulnerabilização produzem a despossessão moral de vastos segmentos da população. A globalização impõe a lógica do mercado e, ao mesmo tempo, cria uma massa marginal. A segregação residencial emerge como forma de gestão social dessa massa marginal. A modernização, realizada pela acumulação liberal, ao mesmo tempo em que promove, quebra os laços da integração social.

Muitos bairros das cidades brasileiras conhecem uma trajetória semelhante ao que sucedeu com os guetos negros das cidades americanas, ou seja, em vias de se transformar em um dispositivo institucional que isola e encarcera os excluídos.

[...] o gueto é um dispositivo socioespacial que permite a um grupo estatutário dominante em um quadro urbano desterrar e explorar um grupo dominado portador de um capital simbólico negativo, isto é, uma propriedade corporal percebida como fator capaz de tornar qualquer contato com ele degradante, em virtude daquilo 
que Max Weber chama de "estimação social negativa da honra". Em outros termos, um gueto é uma relação etnoracial de controle e de fechamento composta de quatro elementos: estigma, coação, confinamento territorial e segregação institucional. (Wacquant, 2001b, p. 34).

A democracia exige a participação de pessoas dotadas de autonomia moral, sem o que não são possíveis nem as deliberações nem as escolhas conscientes e responsáveis. Por sua vez, essa autonomia moral demanda um grau razoável de independência e segurança econômicas. Estamos de acordo com a opinião de J. Nun (1996) sobre as possibilidades de a consolidação de uma "democracia representativa excludente", como conseqüência da prevalência de extremas desigualdades nas cidades, gerar situações de vulnerabilidade e riscos sociais que ameaçam a segurança física e social (identidade individual e coletiva) de amplos segmentos da população. Isso equivale a dizer que em nossas cidades podem existir regimes políticos democráticos pouco representativos, nos quais apenas alguns desfrutariam da real condição de cidadania. Neste contexto político, a tendência seria a permanência de formas perversas de integração social que se encarnam no clientelismo, na criminalidade, no comércio ilegal, na proliferação de guetos e populações marginalizadas e na persistência de modos brutais de exploração da mão-de-obra.

Será que o "ar da cidade brasileira emancipará" o homem integrante das massas marginais em vias de exclusão territorial? Não temos a resposta, mas podemos afirmar que, como na passagem do feudalismo para o capitalismo, será na cidade, no enfrentamento das tendências à restauração dos laços de dominação, próprios do Ancien Regime, que se travará a luta por uma sociedade democrática. Para tanto, temos que adotar a palavra de ordem proposta pelo sociólogo Boaventura de Souza Santos: democratizar a democracia! A sua concretização, porém, passa pelo combate aos novos mecanismos de espoliação urbana, fundados na segregação e no isolamento 
territoriais, combate pelo qual poderemos conciliar, finalmente, a cidade, a democracia e a justiça social.

\section{Notas}

1 Nas palavras de Oliveira (1982, p. 50-51), “as cidades são por excelência a expressão urbana dessa nova estrutura de classes, onde o peso das classes médias emerge com enorme força, com enorme gravitação, tendo em vista o tipo de organização que o capitalismo internacional criou ao projetar suas empresas dentro da sociedade brasileira. Isso também tem importância do ponto de vista político. A enorme gravitação das classes médias no Brasil, vista sob outro aspecto, é uma das bases do autoritarismo da sociedade brasileira. Do ponto de vista do urbano, das relações entre Estado e o urbano, estas novas classes médias criaram demandas dentro das cidades. E o Estado hoje, do ponto do vista de sua relação com o urbano, entre outros aspectos importantes, saliento, é em grande maioria determinado pela demanda das classes médias dentro das cidades."

2 No entanto, esse índice é significativamente distante da Região Metropolitana de Porto Alegre que, destacando-se das demais áreas, ostentava o mais alto nível de associação e filiação a organizações associativas (38\%). Este e os demais indicadores levantados na pesquisa nos permitem aferir que a cultura cívica existente na Região Metropolitana de Porto Alegre se diferencia das demais regiões metropolitanas incluídas na pesquisa.

Contemporary challenges of the construction of the citizenship in Brazilian metropolis

Abstract: The article proposes the reflection on the contemporary challenges of the construction of the citizenship in Brazil resulting from the effects of the tendencies to the residential segregation 
and segmentation of the great cities on the civic culture that based political relations on the processes of democratization occurred in the developed societies.

Keywords: citizenship, democracy, metropolises, social inequalities, residential segregation

\section{Referências}

BRAUDEL, R. Civilização material, economia e capitalismo séculos $X V$ XVIII. São Paulo: Martins Fontes, 1996.

CASTEL, R. Les métamorphoses de la question sociale: une chronique du salariat. Paris: Fayard, 1995.

FREITAG, B. Cidade dos homens. Rio de Janeiro: Tempo Brasileiro, 2002.

HARVEY, D. A justiça social e a cidade. São Paulo: Hucitec, 1980.

LESSA, C.; DAIN, S. Capitalismo associado: algumas referências para o tema Estado e Desenvolvimento. In: DESENVOLVIMENTO e capitalismo no Brasil. São Paulo: Brasiliense, 1984.

LIFSCHITZ, J. Correndo atrás: estratégias de trabalho e de consumo em uma favela carioca. 1999. Dissertação (Mestrado) - Instituto Universitário do Estado do Rio de Janeiro, 1999.

NUN, J. Marginalidad y exclusión social. México: Fondo de Cultura Económica, 2001.

KATZNELSON, I. Marxim and the city. New York: Calendron Press Oxford, 1992.

KOWARICK, L. A espoliação urbana. Rio de Janeiro: Paz e Terra, 1979.

RENNÓ JUNIOR, L. R. Indivíduo, comunidade e cultura: fronteiras do debate entre liberdade e comunitarismo no Brasil. In: ARAÚJO, E. P. et al. (Orgs.). Política e valores. Brasília: UnB, 2000. 
RIBEIRO, L. C. Q. Capital imobiliário no Rio de Janeiro: dinâmica e impasses. Estudos e Debates, v. 5, p. 5-32, 1985.

RIBEIRO, L. C. Q.; LAGO, L. (Orgs.). Acumulação urbana e a cidade. Rio de Janeiro: IPPUR/UFRJ, 1992.

RIBEIRO, L. C. Q. A incorporação imobiliária: características, dinâmica e impasses. In: RIBEIRO, L.C.Q.; AZEVEDO, S. (Orgs.). A crise da moradia nas grandes cidades. Rio de Janeiro: UFRJ, 1996.

RIBEIRO, L. C. Dos cortiços aos condomínios fechados: as formas de produção da moradia na cidade do Rio de Janeiro. Rio de Janeiro: Civilização Brasileira; IPPUR/UFRJ, FASE, 1997. 352 p

OLIVEIRA, F. O Estado e o Urbano no Brasil. Revista Estudos e Debates, n. 6, jun./set. 1982.

OLIVEIRA, Francisco de. A ilusão do Estado brasileiro. Teoria e debate, n. 44, p. 33, abr./jun. 2000. Disponível em: $<$ http://www.fundacaoperseuabramo.org.br/td/td44/td44_nacional.htm>.

SOARES, L. E. Meu casaco de general. São Paulo: Companhia das Letras, 2000.

POLANYI, K. A grande transformação: as origens da nossa época. Rio de Janeiro: Campus, 2000.

WACQUANT, L. Os condenados da cidade. Rio de Janeiro: Revan, Observatório das Metrópoles, 2001a.

WACQUANT, L. Punir os pobres: a nova gestão da miséria nos Estados Unidos. Rio de Janeiro: Freitas Bastos, Instituto de Criminologia, 2001b. 